\title{
Influence of the different variants of the surface treatment on the durability of forging dies made of Unimax steel
}

\author{
Marek Hawryluk $^{1} \cdot$ Daniel Dobras $^{1} \cdot$ Marcin Kaszuba $^{1} \cdot$ Paweł Widomski $^{1} \cdot$ Jacek Ziemba $^{1}$
}

Received: 3 December 2019 / Accepted: 22 April 2020 / Published online: 4 May 2020

(C) The Author(s) 2020

\begin{abstract}
The study performs an analysis as well as makes a comparison of the durability of forging tools used in the die forging process made of high-strength steel Unimax. For tool steel WCL (1.2343 according to DIN), which has been applied so far, the obtained average durability has been at the level of about 6000 forgings. Additionally, in order to increase the durability of the Unimax material, two surface treatment variants were applied: in the form of ion nitriding (for nitrides A) and gas nitriding together with a PVD-Alvin coating, which were compared with the results for an insert without surface treatment. For each variant, three tools were produced, in order to obtain repeatable and verified results. In the first place, an analysis of the working conditions of the tools was performed through thorough observations of the industrial forging process, particularly the tribological conditions, including the manner of lubrication as well as the temperature distributions, by means of, among others, thermovisual examinations. Additionally, numerical modeling of the process was carried out with the purpose of a more accurate analysis of the tool work in contact. Next, a detailed analysis of the exploitation of the worn tools was performed, including a macroscopic and geometrical analysis through 3D scanning, microscopic optical, and SEM tests as well as microhardness measurements. The obtained results demonstrated that only the application of the new material, Unimax, itself caused a durability increase by 2.5 times with regard to the WCL steel used so far. In turn, with the application of additional surface engineering techniques, Unimax tools characterized in better operational properties (high thermal and abrasive wear resistance at elevated temperatures), which made it possible to forge over four times more forgings, i.e., 26,000 items, after nitriding with a PVD-Alvin coating had been applied to the tool.
\end{abstract}

Keywords Hot die forging $\cdot$ Tool durability $\cdot$ Hot work steels $\cdot$ Surface engineering techniques $\cdot$ Operation of forging tools

Marek Hawryluk

marek.hawryluk@pwr.edu.pl

Daniel Dobras

daniel.dobras@pwr.edu.pl

Marcin Kaszuba

marcin.kaszuba@pwr.edu.pl

Paweł Widomski

pawel.widomski@pwr.edu.pl

Jacek Ziemba

jacek.ziemba@pwr.edu.pl

1 Department of Metal Forming and Metrology, Wrocław University of Science and Technology, Wrocław, Poland

\section{Introduction}

The durability of forging tools is an important as well as difficult issue in both the scientific and economical aspect, in the case of plants producing forgings [1,2]. This results from the significant share of the tool costs in the total costs calculated based on the production of one single forging. That is why, often, the durability itself is described by the number of forgings which has properly produced geometry and quality wise by the given tool. At present, it is estimated that the cost of a forging is on average about $8-15 \%$ of the cost of the tools, whereas it can reach even $30 \%$ in the case of small production series, and in extreme cases, for complicated shapes of steel forgings or for austenitic forgings, it can be as high as 50-60\% $[3,4]$ and also lubrication [5]. A majority of these costs is 

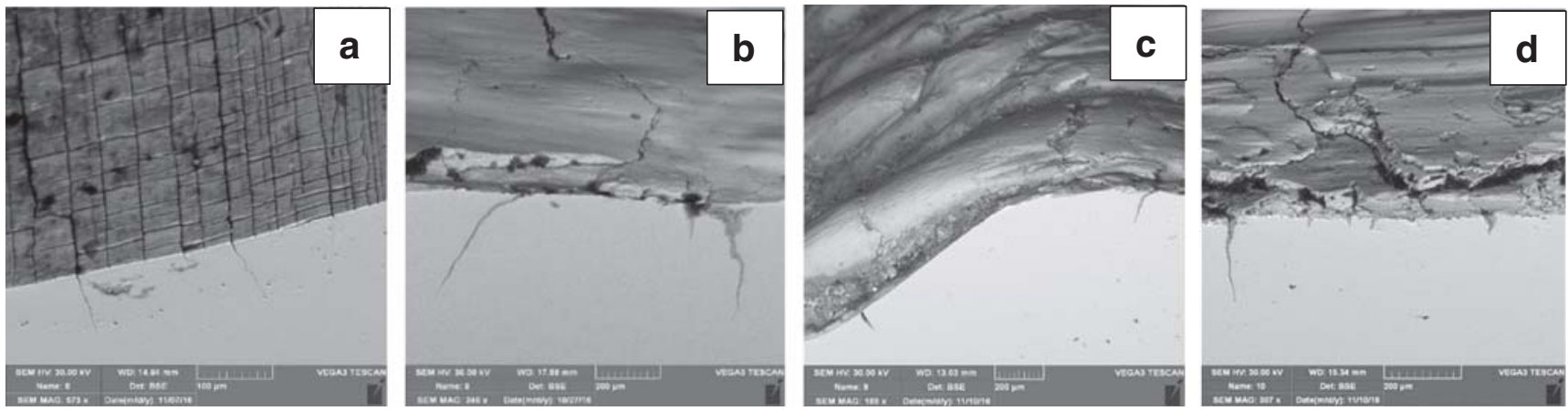

Fig. 1 The most common degradation mechanisms of forging tools. a Thermo-mechanical fatigue. b Plastic deformation. c Abrasive wear. d Oxidation

covered by the dies or die inserts. The remaining instrumentation elements, such as mounts and flattening plates, undergo wear to a much lesser degree. In turn, trimming dies and piercing dies, which wear quite quickly, can be easily regenerated through pad welding and regeneration of only the cutting edges, which significantly lowers their share in the total cost of the forging [6].

The wear of forging tools used in hot forging processes is complicated and difficult to analyze, as it is affected by many phenomena, which often occur simultaneously [7]. Among the most important ones, we can name thermo-mechanical fatigue, plastic deformation, abrasive wear, and oxidation (Fig. 1). All these factors simultaneously contribute to the wear of forging tools, while the share of the effect of the particular factors is different depending on the type of the tool (its size, shape, and production manner) as well as on the operation conditions (type of the forging aggregate, pressures, process temperature, etc.) [8]. In the case of die inserts whose hardness is significantly higher (the hardness of tool steel after thermal treatment reaches even 58-60 HRC, i.e., 650$700 \mathrm{HV}$ ), the plastic deformation does not take place very quickly [6]. Due to high hardness, numerous cracks are formed on the working surface, which is described as the effect of the mechanism of thermal and mechanical fatigue [9]. These cracks form a characteristic network of a regular or irregular shape in the surface, visible in Fig. 1a. Usually, during further operation, these cracks become deeper and wider as a result of the accumulating oxides, which work as "wedges" [7]. The deepened cracks gradually transform into grooves, which are usually formed parallel to the direction of the material flow. The surface of the die near the groove undergoes local deepening, and the edges of the cracks become smooth (Fig. 1c). On the surfaces, one can also observe adhesive wear that is oxidation and tearing-off of fragments from the die surface (Fig. 1d). The share of particular mechanisms in the total wear of the given tool can vary during the operation $[7,10]$. As a rule, at the beginning, a network of fatigue cracks appears, and next, abrasive wear, material tempering, and local plastic deformation simultaneously occurs $[11,12]$. Depending on the forging process and its conditions, one can also observe a secondary fatigue crack network originating from both thermal fatigue [13-15] and, intensifying the degradation process, mechanical fatigue [16] as a result of high forming forces. All this causes rapid and accelerated wear as well as tearing-off of increasingly bigger particles of the material, in which case, abrasive wear is not necessarily the dominant phenomenon [3].

Often, the biggest share in the wear of tools used in hot forging processes is also attributed to abrasive wear, while, in fact, other mechanisms are dominant, and abrasive wear is only the final and most easily measurable effect. The intensity of the occurrence of the particular mechanisms is significantly affected by the forging conditions, and more precisely the lubrication. In the case of lubricated and cooled tools, thermo-mechanical fatigue is mostly dominant, whereas for non-lubricated and cooled tools, abrasive wear and plastic deformation dominate [4]. The wear of the forging tools as well as the remaining instrumentation causes a change in the geometry of the product, and any surface flaws of the tools (cracks, defects) are reflected in the forged product, affecting its quality [17-19].

There are many methods of improving the durability of forging tools $[1,4]$. Procedures aiming at an improvement of a tool's durability are usually performed in three different directions. The first one takes into account the technological and construction aspects of the forging process [20]. Here, the most crucial is the optimization of the construction of dies and impressions. As the finishing impression has to reflect the ready forging and it cannot be changed without consulting the recipient, the modification usually refers only to the roughing passes and auxiliary impressions [21]. Through the proper selection of shape, the aim is to synchronize the wear of the roughing passes and finishing impressions, especially when they are in the same die [22]. This is also supported by modern production supervision systems, which stabilize the process and eliminate errors [23], (https://www. thomasnet.com/articles/custom-manufacturing-fabricating/ forging-parts-supplies/). The second direction concerns modification of the material used to make the tools [24]. The steels used to produce die impressions for presses have to exhibit high strength, hardness, and abrasive resistance, at 
Table 1 Chemical composition of the Unimax steel compared with the standard WCL steel used so far

\begin{tabular}{llllllll}
\hline $\begin{array}{l}\text { Chemical content } \\
\text { Material (\%) }\end{array}$ & C & Mn & Si & Cr & Mo & V \\
\hline X37CrMoV5-1 (1.2343, WCL) & $0.32-0.42$ & $0.2-0.5$ & $0.8-1.2$ & $4.5-5.5$ & $1.2-1.5$ & $0.3-0.5$ & Residue \\
Unimax & 0.5 & 0.2 & 0.5 & 5.0 & 2.3 & 0.5 & Residue \\
C45/1.0503 & $0.42-0.50$ & $0.50-0.80$ & Max 0.40 & Max 0.40 & Max 0.10 & - \\
\hline
\end{tabular}

the same time characterizing in proper ductility at the working temperature $[25,26]$. The above-mentioned properties can be obtained through the proper selection of the steel's chemical composition. The small content of carbon $(0.30 \div 0.55 \%)$ ensures ductility, whereas alloy elements such as tungsten, molybdenum, and vanadium maintain high hardness at elevated temperature $[27,28]$. From this reason, the new hot work steels are used and developed, like Supreme, Thermodur, and Unimax steel. For example, the Unimax steel has been found to be more wear-resistant than conventional tool steels such as H11 or H13. The publication presents a comparison showing that tools made of Unimax have up to $250 \%$ longer durability [29]. In addition, in other works, the resistance of this steel to abrasive wear was analyzed [30, 31], which is much higher compared with other steels. The application of Unimax steel as a material for hot forging tools [32] can also be pointed out, also as an excellent substrate for nitriding [33] and as a substrate for hybrid layers combining nitriding and PVD coatings [34].

In order to obtain the assumed mechanical properties, it is necessary to perform the appropriate thermal treatment, which usually consists of quenching and, performed twice, high tempering [34]. The third direction refers to modern surface engineering techniques [35]. Among the most popular ones, we can name welding techniques (pad welding), thermo-chemical treatment (nitriding, etc.), beam techniques, and mechanical methods (shot peening) as well as hybrid layers and techniques $[36,37]$. There are no clear criteria for the selection of a particular durability improvement method, as each case should be analyzed individually with respect to the conditions present during the forging process [3]. Also, oftentimes, certain methods are combined in order to obtain the optimal solution or the effect of synergy, which makes it possible to increase the durability of forging tools. An important criterion is also the availability of solutions, of which some require access to a big and costly industrial infrastructure (nitriding furnaces, coating application apparatus). The selected improvement manner has to be justified economically, and it should be analyzed whether the gain resulting from an increase of tool life will be higher than the sum of the expenses (material, machining, thermal and thermo-chemical treatment) [38].

\section{Research objective and methodology}

In the investigations, an attempt was made at increasing the hardness of the tools used so far (upper die inserts applied in the roughing operation) through the use of another tool material - steel with the commercial name Unimax. Also, for this material, two surface treatment variants were applied - in the form of ion nitriding (for nitrides $\alpha$ ) and gas nitriding together with the application of a PVD-Alvin coating - which were compared with the results for an insert not subjected to surface treatment. The properties of the newly applied material make it possible for the Unimax steel to find its application for tools assigned for hot and semi-hot operations, which require both high hardness and ductility. Alvin coating is a nanocomposite CrAlSiN coating with high chromium content and high resistance to oxidation and adhesion to the shaped material of the tool (https:// shm-cz.cz/pl/powloki-pvd/). The chemical compositions of both steels have been compared in Table 1. It can be inferred from the comparison that the Unimax steel contains more molybdenum (Mo) and slightly more carbon, with a similar share of the other alloy additions. The recommended quenching and tempering is constituted by the following: quenching at $1025^{\circ} \mathrm{C}$ as well as, performed twice, tempering at minimum $525^{\circ} \mathrm{C}$, which guarantees hardness at the level of 56-58 HRC. Table 2 presents the denotations as well as the applied thermo-chemical treatment variants together with the number of performed cycles.

The prepared tools underwent performance tests (three tools for each variant), where, by means of each of the three variants, the maximal number of forgings fulfilling the required criteria was made. Next, the tools, after their operation, were subjected to an in-depth analysis in order to compare and
Table 2 Data concerning the state of the examined inserts and the number of cycles performed by them

\begin{tabular}{llll}
\hline Denotation & No. 1 & No. 2 & No. 3 \\
\hline Surface engineering techniques & - & $\begin{array}{c}\text { Nitriding the SECO } \\
\text { company on } \alpha \text { nitrides }\end{array}$ & $\begin{array}{l}\text { Nitriding in the Jawor Forge, } \\
\text { PVD-SHM-ALVIN coating } \\
\text { Number of cycles }\end{array}$ \\
\hline
\end{tabular}


evaluate the effectiveness of the durability improvement using another material.

\section{Test results}

\subsection{Analysis of the industrial forging process}

An analysis of the industrial process of producing a yoke-type forging (a key element of the steering column in motor cars) was performed with the aim to determine the performance conditions of the upper die inserts used during the operation of roughing. The examinations were supported by temperature measurements with the use of a thermovision camera as well as the results of numerical modeling. The forging process is realized in four operations on a Massey press with the load of $13 \mathrm{MN}$ (Fig. 2). The tools visible in Fig. 2 - die inserts - in the case of the standard forging process, are made of steel X37CrMoV5-1 (1.2343-WCL according to DIN), which was thermally treated through quenching from $1000{ }^{\circ} \mathrm{C}$ and twofold tempering at $540{ }^{\circ} \mathrm{C}$, and they characterize in diversified durability. The initial charge material made of C45 (1.0503 according to DIN) in the shape of a cylinder with a diameter of $35 \mathrm{~mm}$ and a length of $53 \mathrm{~mm}$ heated inductively from the ambient temperature to the target equals $1150{ }^{\circ} \mathrm{C}$, for about 2 min. The chemical composition of steel is shown in Table 1 . Immediately after the forging process, the hot trimming of flash takes place. The full production cycle of one forging is about 14-15 s, which gives about four pieces per minute and about 240 forgings/hour. The quality control is carried out every 300 forgings. For lubrication and cooling, an automated lubricating device developed and built by the authors was used, in which the lubricant was a mixture of graphite with water in a ratio of 1:20 in a dose of lubricant $10 \mathrm{ml}$ during spraying for $2 \mathrm{~s}$. This device allows for precise and repeatable dosing with simultaneous possibility of varying the proportions for subsequent nozzles as well as the possibility of free setting of the air blow sequence and application of lubricant. Detailed information on the developed lubrication system ensuring optimal and repeatable tribological conditions, which translates into quality and reduction of production costs, is presented in the papers works [39-41].

The lowest durability is exhibited by the roughing inserts (the middle center - the biggest plastic deformations as well as pressures and forging forces). Therefore, for these tools, steps aiming at increasing their durability were taken. In the first place, the forging process parameters were analyzed, especially the temperature of the forging and the tool as well as the pressures present in the contact between the surface of the working pattern and the material of the forging. To that end, a measurement of the tool temperature was made by means of a thermovision camera, and a MES simulation of the forging process was performed. The temperature measurement results are shown in Fig. 3.

In the thermogram shown in Fig. 3, it is possible to determine the value of the temperature on the working surface of the roughing pass and the finishing impression, which equals about $250{ }^{\circ} \mathrm{C}$. The values are in accordance with the technology, as the tool temperature recommended for this process equals $250-300{ }^{\circ} \mathrm{C}$. The measurement was made directly after the forging was removed from the tool. Generally speaking, the temperature of the forging tools periodically changes, as the die impressions rapidly heat up in contact with the hot forging and then cool down when they give up heat into the body of the tool as well as during the evaporation of the cooling and lubricating liquid. The precise values of temperature and pressure in contact present in the forging process

a

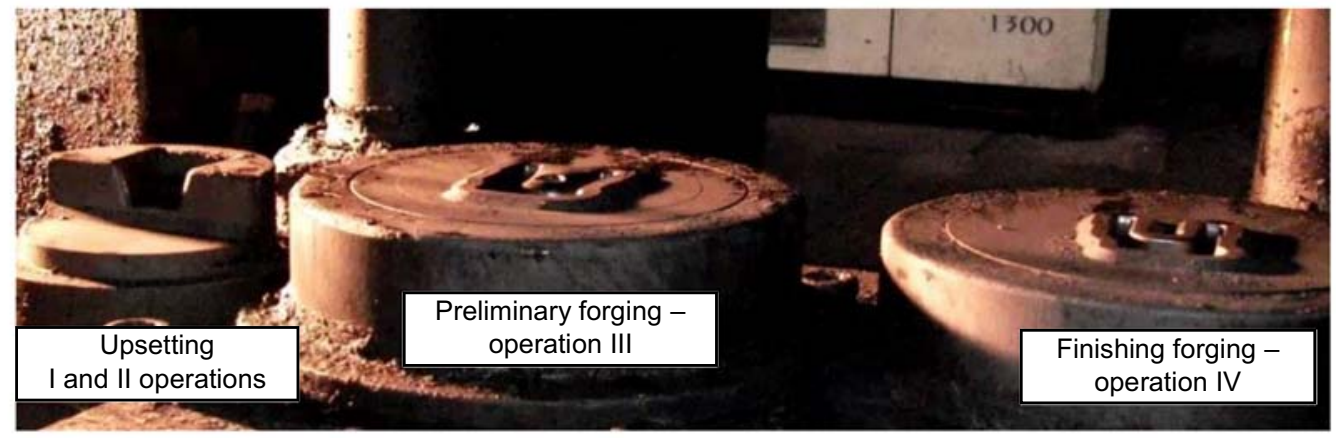

b

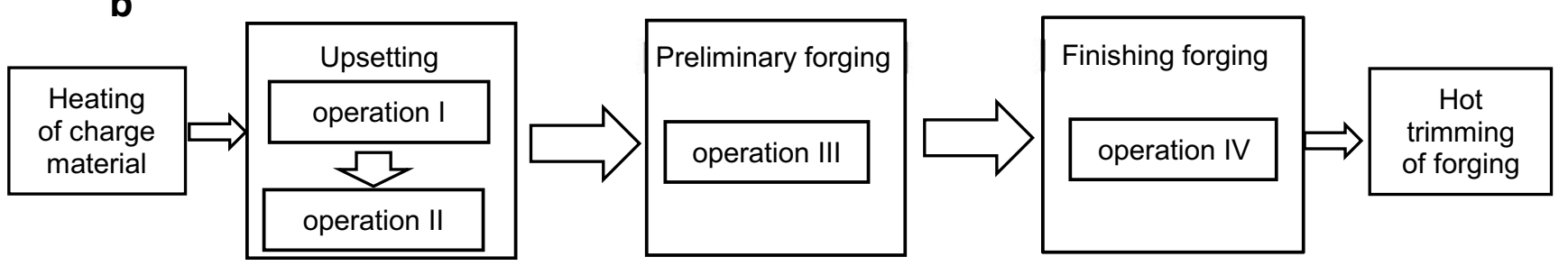

Fig. 2 The view of a the lower tools fixed on the Massey 13 MN press table-work station. $\mathbf{b}$ The schematic diagram 
Fig. 3 Tool thermogram - a view directly after spraying performed by the cooling and lubricating nozzles

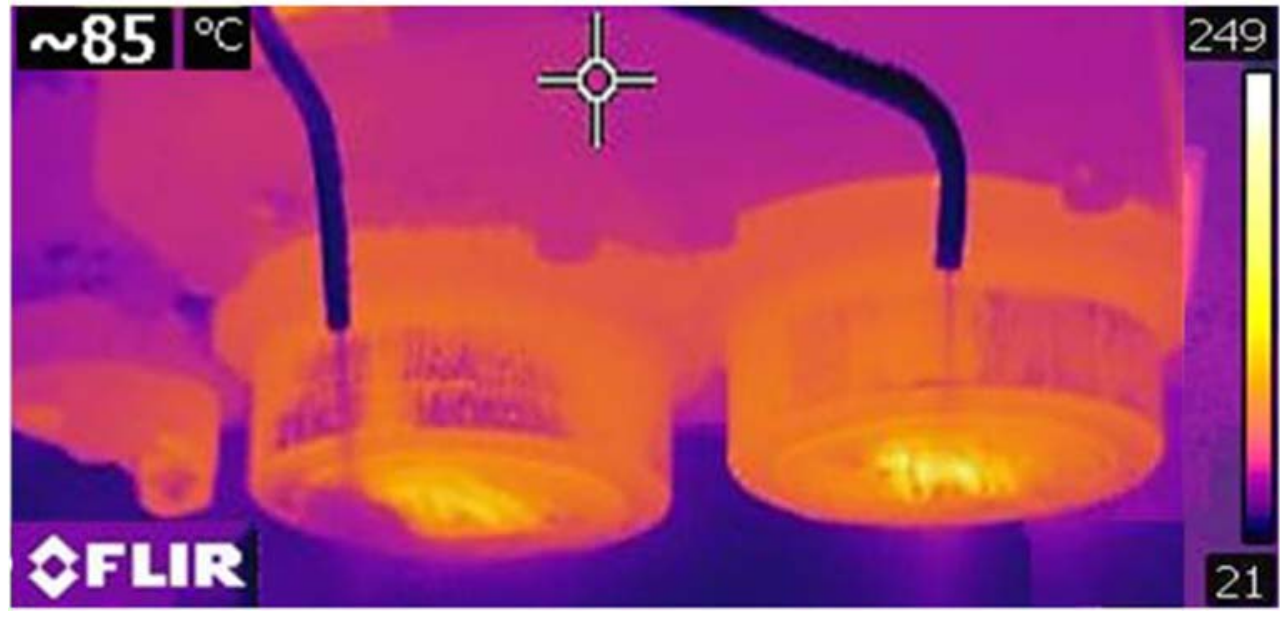

were determined through numerical modeling in the Forge software, in which the values of temperature and pressure, as well as distribution of abrasive wear on the tool surface, were determined. Selected results of this simulation are shown in Fig. 4, where one can see that the highest pressures are present in the central part, between the fork arms of the forging, which results from the preform being the most deformed in this area.

\subsection{Performance tests and macroscopic observations of forging tools}

During the tests, all the selected tools (three items for each of the three variants) were operating until reaching the maximal accepted wear. The decision of removing the tool from further operation was made based on the quality control performed on the forgings during the process. During the tests, with the use of the selected inserts for the first variant - the Unimax steel without an additional thermo-chemical treatment - the average of 16,000 items were produced, which corresponds to an over 2.5 times higher average of tool durability in this process in respect of the tool material used so far, i.e., WCL steel. In turn, under similar forging conditions, by means of inserts made of the Unimax steel nitrided for alpha nitrides (variant II), as many as 16,000 forgings were produced, while for the tools made of Unimax steels nitrided with an Alvin layer (variant III), the mean durability was as much as 26,000 forgings. After the tests, in the first place, the tools underwent a macroscopic analysis. The results of the macroscopic comparative analysis for the representative inserts, for each of the three variants, are presented in Fig. 5.

The non-nitrided tool (Fig. 5a) exhibits numerous traces of abrasive wear on the whole bridge area, especially on the edge, in the spot of the formation of the flash. The abrasive wear has the form of grooves radiating from the center of the die. It is very deep and undesirable, as it may cause big changes in the geometry of the produced forgings. Owing to the application of nitriding, the abrasive wear was reduced, which is confirmed by the image shown in Fig. 5b. It can be inferred from the observations that no abrasive grooves are present on almost the whole surface of the die, which are visible only to a small degree near the ejector. In turn, the hardening of the surface layer through nitriding caused the occurrence of a different wear mechanism, i.e., fatigue cracking, which reveals itself in the form of a network of cracks visible on the surface as well as numerous minor spallings visible on the bridge of the die. In spite of this, it can be stated that the nitriding operation brought a positive result, as it significantly increased the durability, reduced the wear, and made it possible to prolong the tool's performance. In turn, in the case of the tool for variant III (Unimax with gas nitriding and a PVDAlvin coating), it can be noticed that the wear in the whole impression of the insert is similar to that observed for the insert in variant II. In this configuration, the tools operated much longer, reaching the average durability of 26,000 items. The tool wear visible in Fig. 5c has the character of many minor cracks on the surface. This confirms the dominating effect of thermo-mechanical fatigue on the wear, which, at a further stage of performance, is intensified by abrasive wear. The presence of small losses after such a long operation time compared with the non-nitrided tool constitutes a confirmation of the effectiveness of the applied treatment. The periodical control of the exploitation of the inserts for variant III, performed through observations of the geometrical changes and the state of the tools being within the acceptable tolerance scope, enabled such a long operation of these tools and the production of an average of 26 thousand forgings.

\subsection{Tool wear analyzed through surface scanning with a 3D laser scanner}

The subsequent stage of the research was a dimensional analysis, for which the working patterns of the tools were scanned 

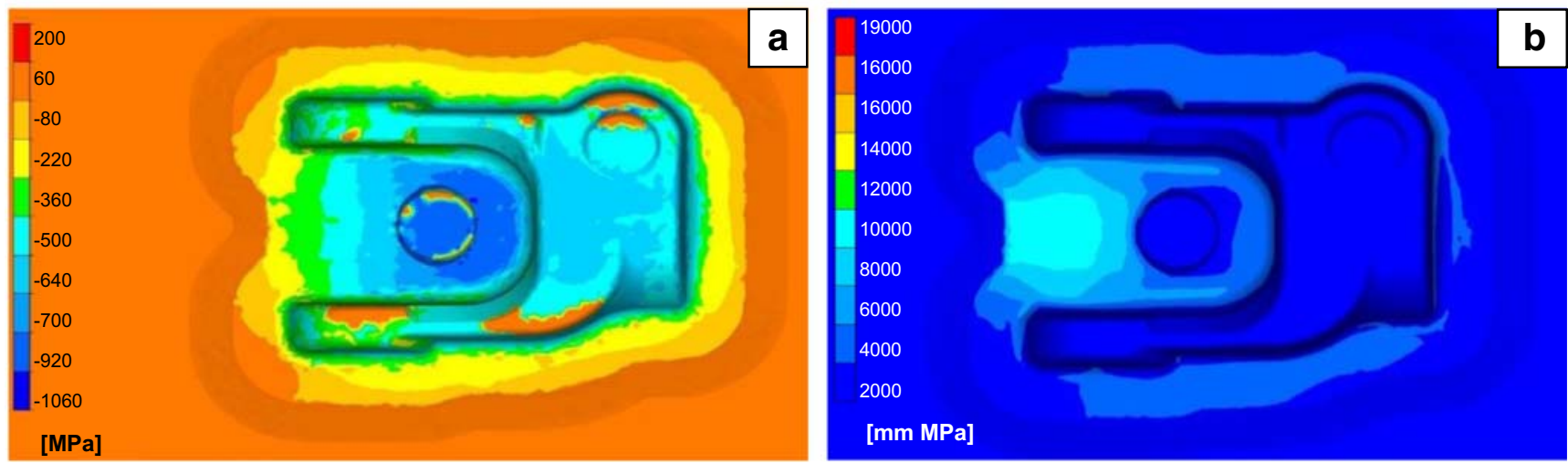

Fig. 4 Result of FEM simulation. a Maximum normal stresses. b Distribution of abrasive wear on the surface of the tool in contact with the forging

after their operation. For the determination of the geometrical loss of the tool material after producing a certain number of forgings, a measuring arm with a laser scanner ROMER Absolute ARM 7520si was used, which enabled 3D scanning of the surface and comparing the obtained results with the CAD model. The comparison was made by means of the local best-fit algorithm in the GOM software. The result of the comparison has been presented in Fig. 6. This made it possible to determine the wear (material loss) in the form of a geometrical distance of the scanned surface from the surface of the CAD model. For the insert denoted as no. 1 (Fig. 6a), one can observe significant material losses marked with dark shades of blue, which assume values reaching $0.8-0.9 \mathrm{~mm}$ in the vicinity of the die insert's bridge. Their localization results from the highest pressure and temperature observed in Fig. 3 and 4 and thus the highest friction in the forging's contact with the tool in those areas.
Also for this tool, one should note the deep losses situated on the bridge, which locally assume the shape of deep pulling out. In the remaining part of the bridge, one can see areas with a smaller loss, at the level of 0.4-0.5 mm, where, under magnification, a large number of vertical grooves is visible. While analyzing the wear of the insert made of the Unimax steel after nitriding for alpha nitrides (Fig. 6b), which worked through the same number of cycles, one can notice that the global wear on this tool is, qualitatively and quantitatively, much smaller, and the local material losses are about twice as small. On this insert, we can also see, marked with blue, local wear areas with the maximal depth of $0.44 \mathrm{~mm}$, situated near the bridge on the side of the stem as well as arms of the yoke-shaped impression. Additionally, one can notice a slightly bigger material loss in the central part of the right arm in respect of the left one, which is probably caused by a non-uniform cooling process. The geometrical analysis of the material loss for the insert denoted as
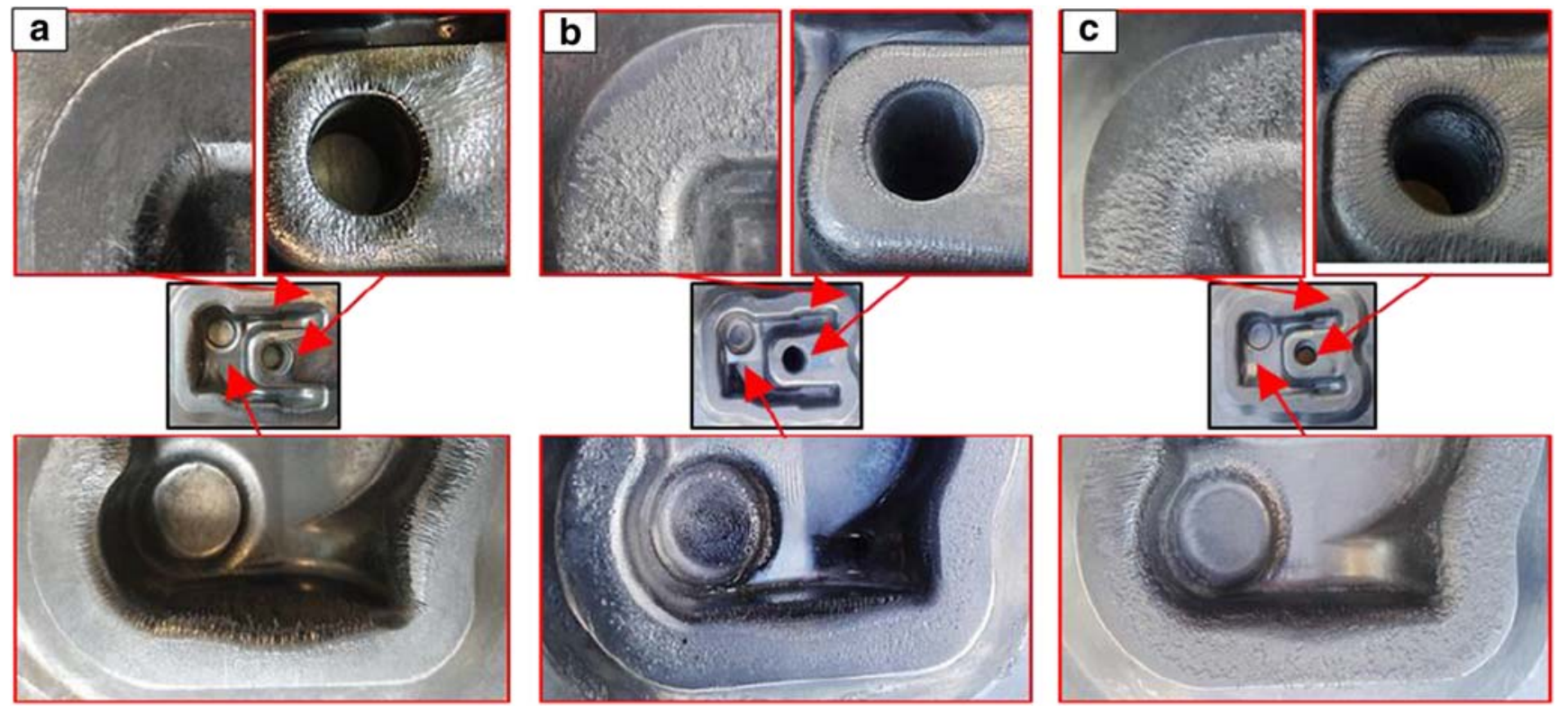

Fig. 5 Macro-view of the lower die insert made of a Unimax steel after 16,000 forging cycles (no. 1), b made of Unimax steel with glow discharge nitriding (for nitrides A) 16 thousand forging cycles (no. 2), and $\mathbf{c}$ made of Unimax steel with gas nitriding together with PVD-Alvin coating after 26,000 pieces (no. 3 ) 

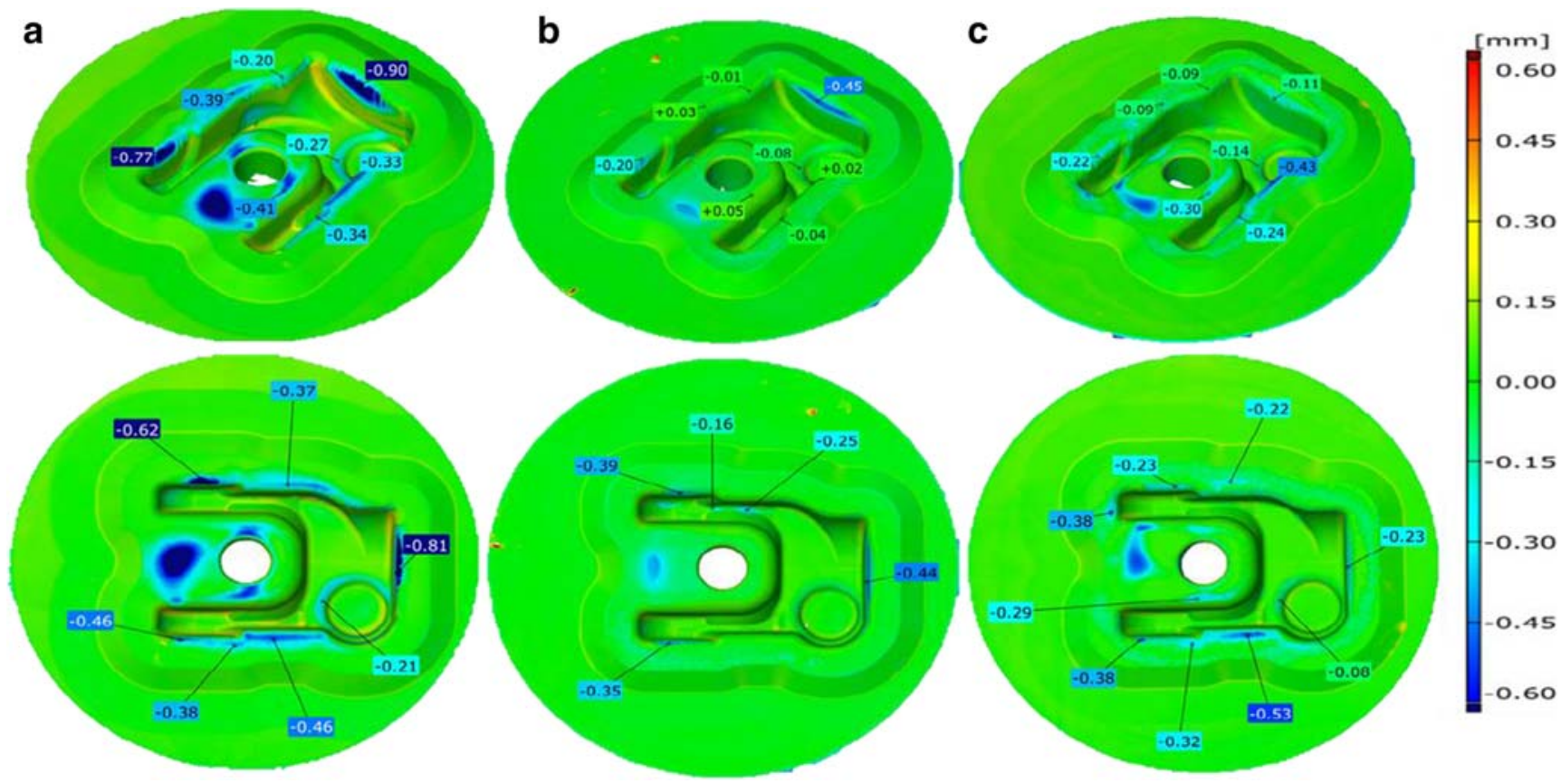

Fig. 6 Geometrical analysis of wear through a comparison of the tools' scans with the CAD model for tools a no. 1, b no. 2 , and $\mathbf{c}$ no. 3

no. 3 shown in Fig. 6c illustrates the abrasive wear on the whole surface. Slightly higher values of material loss $(0.35-0.45 \mathrm{~mm})$ were observed on the front surface between the fork arms, where the forging is placed directly before the forging process, as well as in the initial part of the right arm. In the central part, the pressures are high (Fig. 3) and they are present throughout the whole time of material formation. That is why it is understandable that a small wear is present after such a big number of forging cycles. In turn, in the case of a bigger material loss near the right arm, similarly to the insert denoted as no. 1 , it is probably caused by both the intensive flow of the forging material to the groove and non-optimal lubrication. Despite the observed losses, it can be stated that the tool covered with an additional coating worked through about 10 thousand more cycles than the other tools, and, based on the performed analysis, it can be established that it is worn only slightly more than the insert made of the Unimax steel with the nitriding. It seems that the hybrid layer in the form of nitriding and an applied

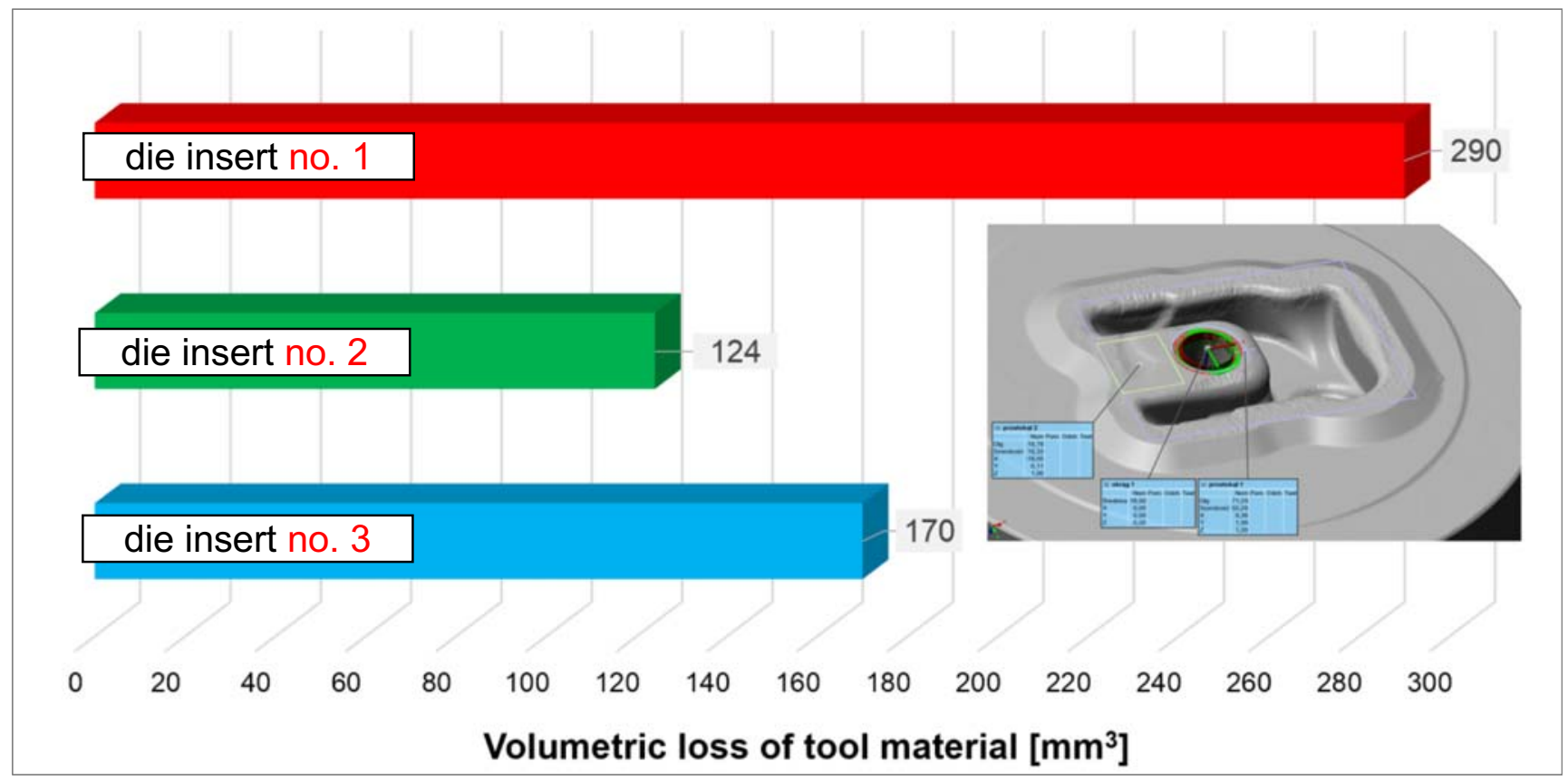

Fig. 7 Comparison of volumetric loss of tool material in shaped area for all analyzed die inserts 
a
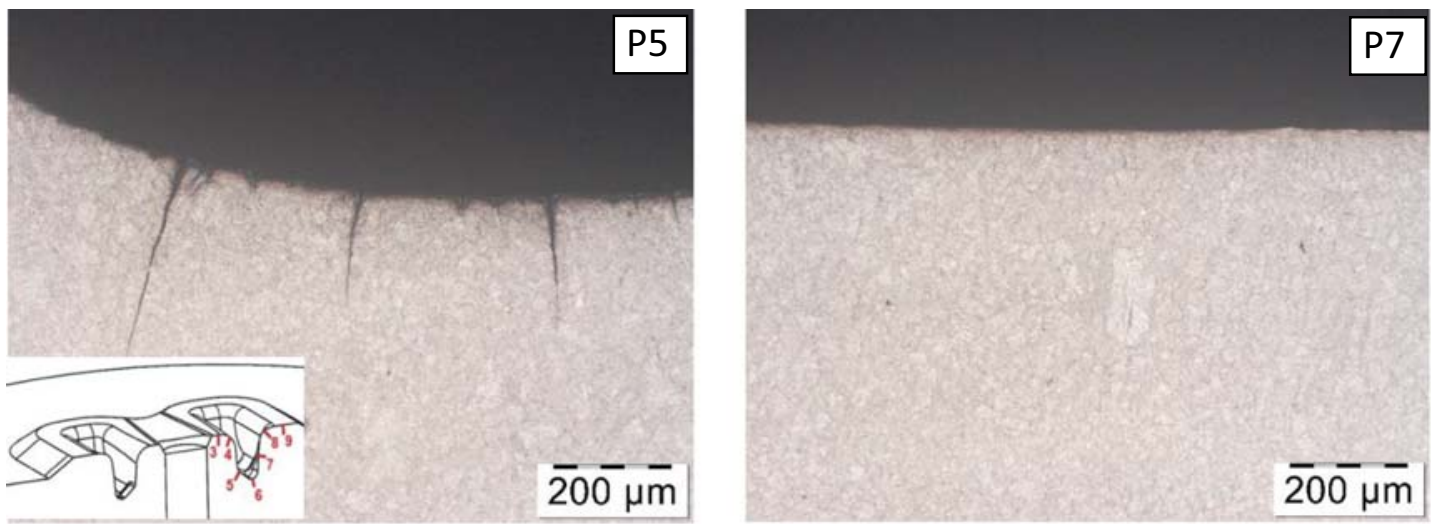

b
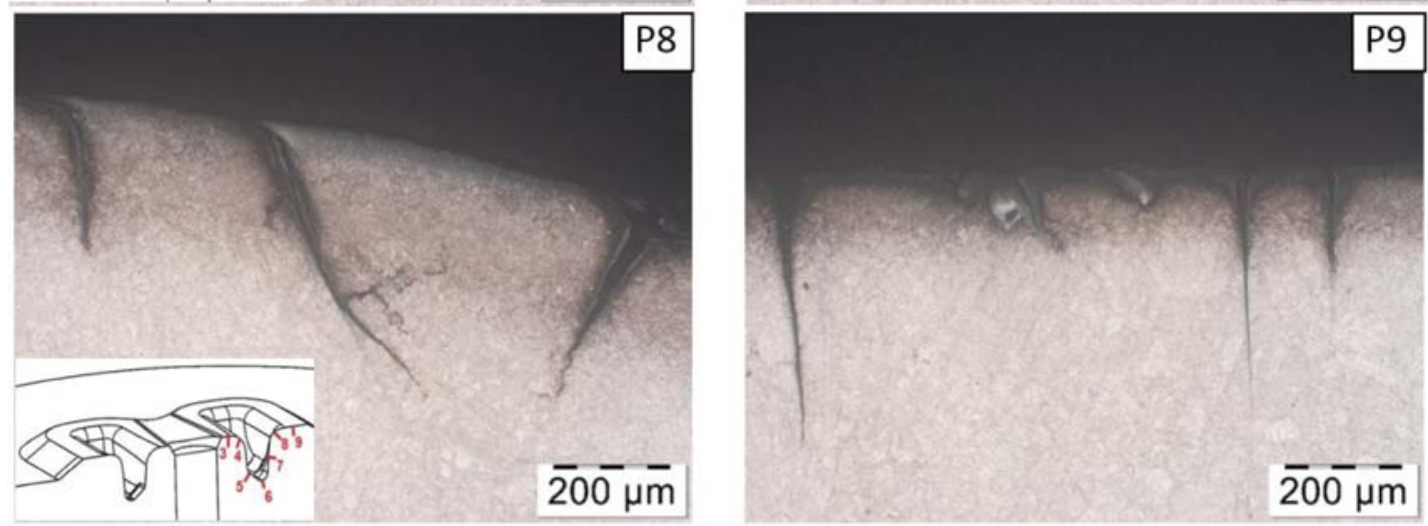

C
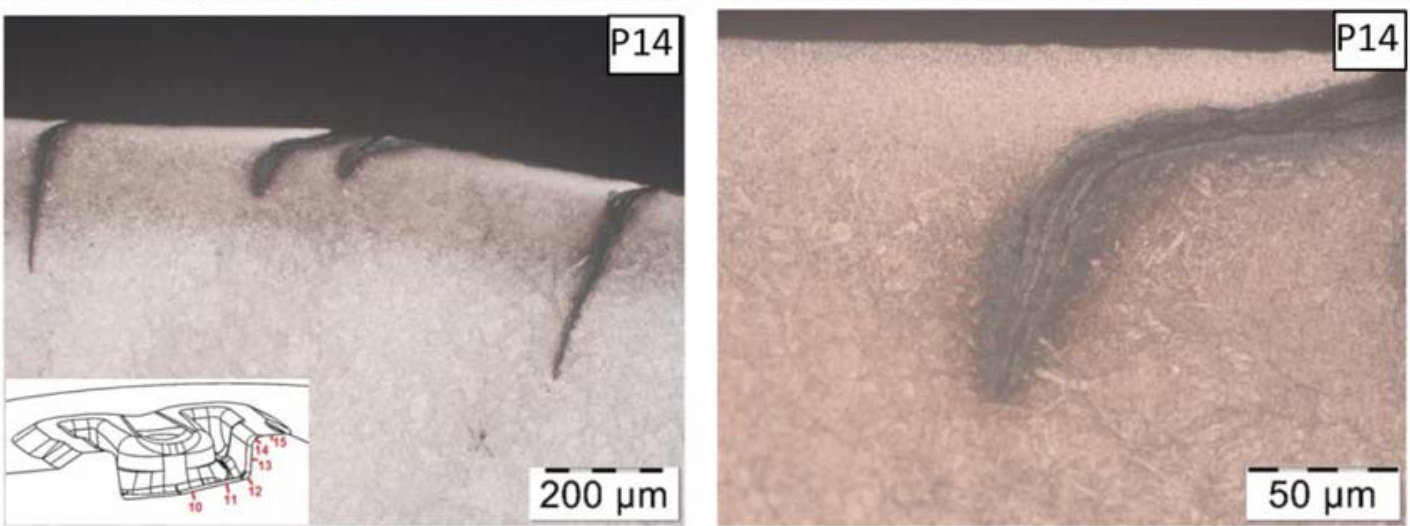

Fig. 8 Microstructure of Unimax steel, inserts no. 1 in points a 5 and 7, b 8 and 9, and $\mathbf{c} 14$ at different magnification

Alvin coating is the best option in the aspect of improving the durability of inserts used for this type of forgings. In order to better illustrate the loss of material on the working surfaces of the tools analyzed, a global volumetric analysis was carried out, which is shown in Fig. 7. Only wear areas that directly shape the forging - without areas near the ejector hole and forming the flash, which is trimmed after forging - between the forging arms are subjected to analysis.

As can be seen in Fig. 7 that the largest volume loss of material was observed for insert no. 1, for which it was $290 \mathrm{~mm}^{3}$, the smallest for insert no. 2, which was about $120 \mathrm{~mm}^{3}$. A slightly larger loss of tool material at $190 \mathrm{~mm}^{3}$ was determined for insert no. 3 , but this die insert produced the largest number of forgings. The volumetric material loss analysis confirmed earlier macroscopic observation and 3D scanning.

\subsection{Microstructure studies in a tool's cross-section}

The analysis of the microstructure and the surface layer as well as the hardness measurements were performed for two different cross sections of the inserts. For each insert, an identical test scheme was applied. The structural test samples were etched in nital, and the microstructure was recorded by means of an optical microscope Olympus GX51, with the use of a camera Olympus DP12.

On the microstructure images for the inserts denoted as no.1, no structure tempering was observed in points 5,7 (Fig. 8a), and 13. Locally, cracks on the insert surface were noticed, especially in the areas where the surface was not flat. A martensitic structure was recorded on the whole examined surface, also at the edge of the sample. In points 3, 4 and 8, 9 
a
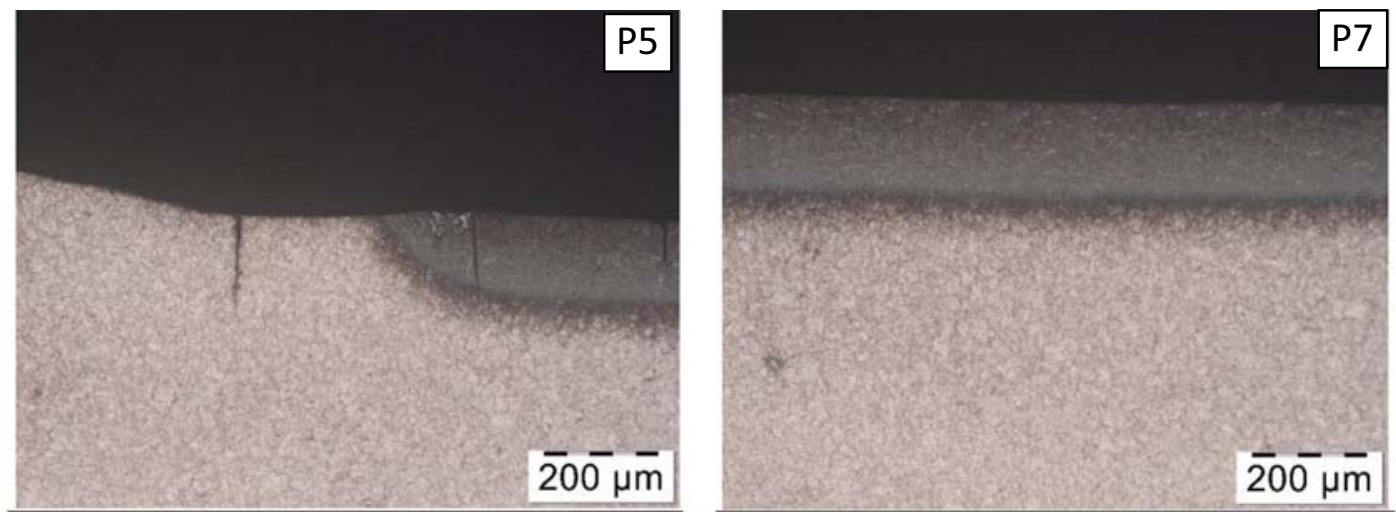

b
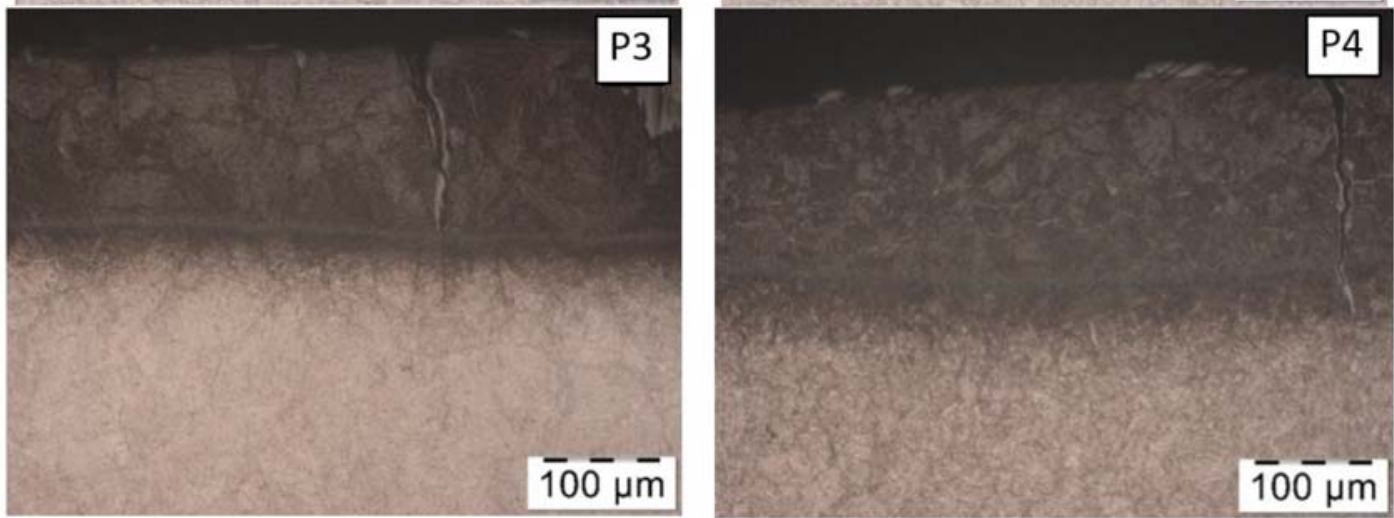

C
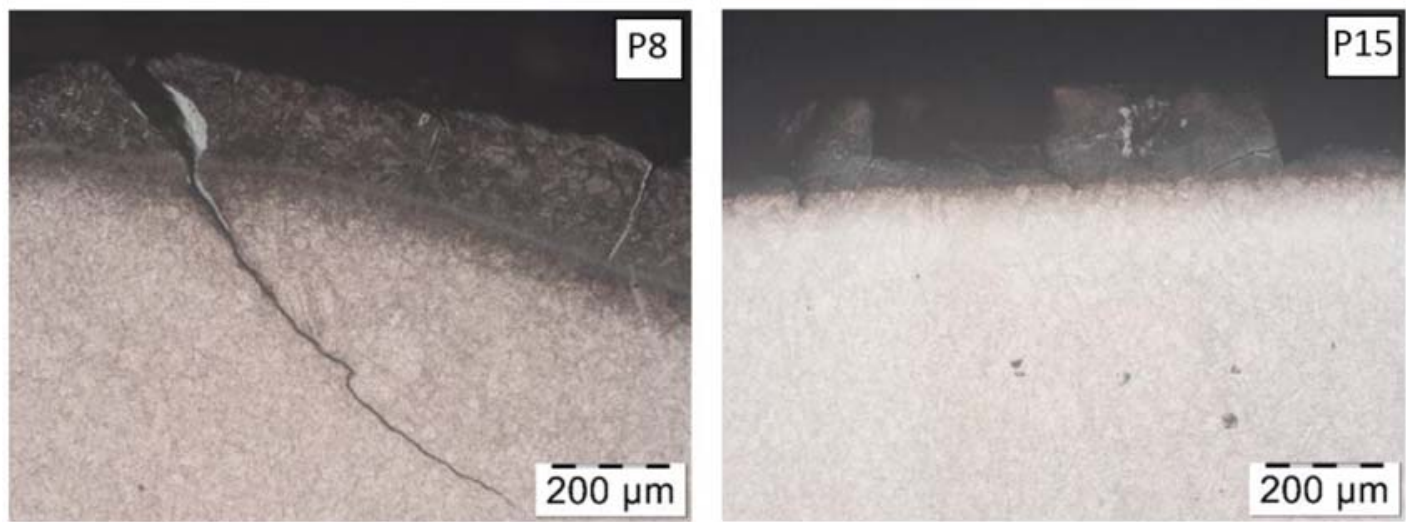

Fig. 9 Microstructure of Unimax steel, inserts no. 2 in points a 5 and 7, b 3 and 5, and $\mathbf{c} 8$ and 15

(Fig. 8b) as well as 14, 15, tempering of the insert's surface layer was observed. The depth of the tempering reaches $200 \mu \mathrm{m}$. On these areas, numerous cracks are present, whose depth equals even $0.5 \mathrm{~mm}$. In the areas of an intensive flow of the forging material, the crack gaps have a characteristic bent shape. This is caused by the flow of the insert material, in the direction of the forging material flow, after the formation of the crack. At the depth of about $50 \mu \mathrm{m}$ from the examined material surface, a divorced pearlite structure was recorded (Fig. 8c).

It is a mixture of spheroidal cementite, which is visible in the form of minor precipitates (as well as other carbides) on the background of recrystallized ferrite. Such a microstructure is present in a material that has been subjected to the operation of a temperature above $650{ }^{\circ} \mathrm{C}$ for a longer period of time.
The inserts no. 2 were nitrided by the SECO/WARWICK company, in such a way so that $\alpha$ phase would be obtained. In the microstructure images, no tempering of the structure was observed in points 5, 7 (Fig. 9a), and 13 .

Locally, cracks on the insert's surface were recorded, especially in the areas where the surface was not flat. The depth of the cracks was usually equal to the depth of the nitrided layer, which did not exceed $200 \mu \mathrm{m}$. No material losses in this area of the nitrided layer were observed. A more fine-grained structure can be observed in points 3 and 4 (Fig. 9b), despite the fact that these points are located close to each other. Additionally, in the nitrided layer in point 3, no white nitride precipitates were noticed, which are present in every other point of the insert. The observations of the surface layer in points 8 and 15 of insert no. 2 did not show tempering of the 

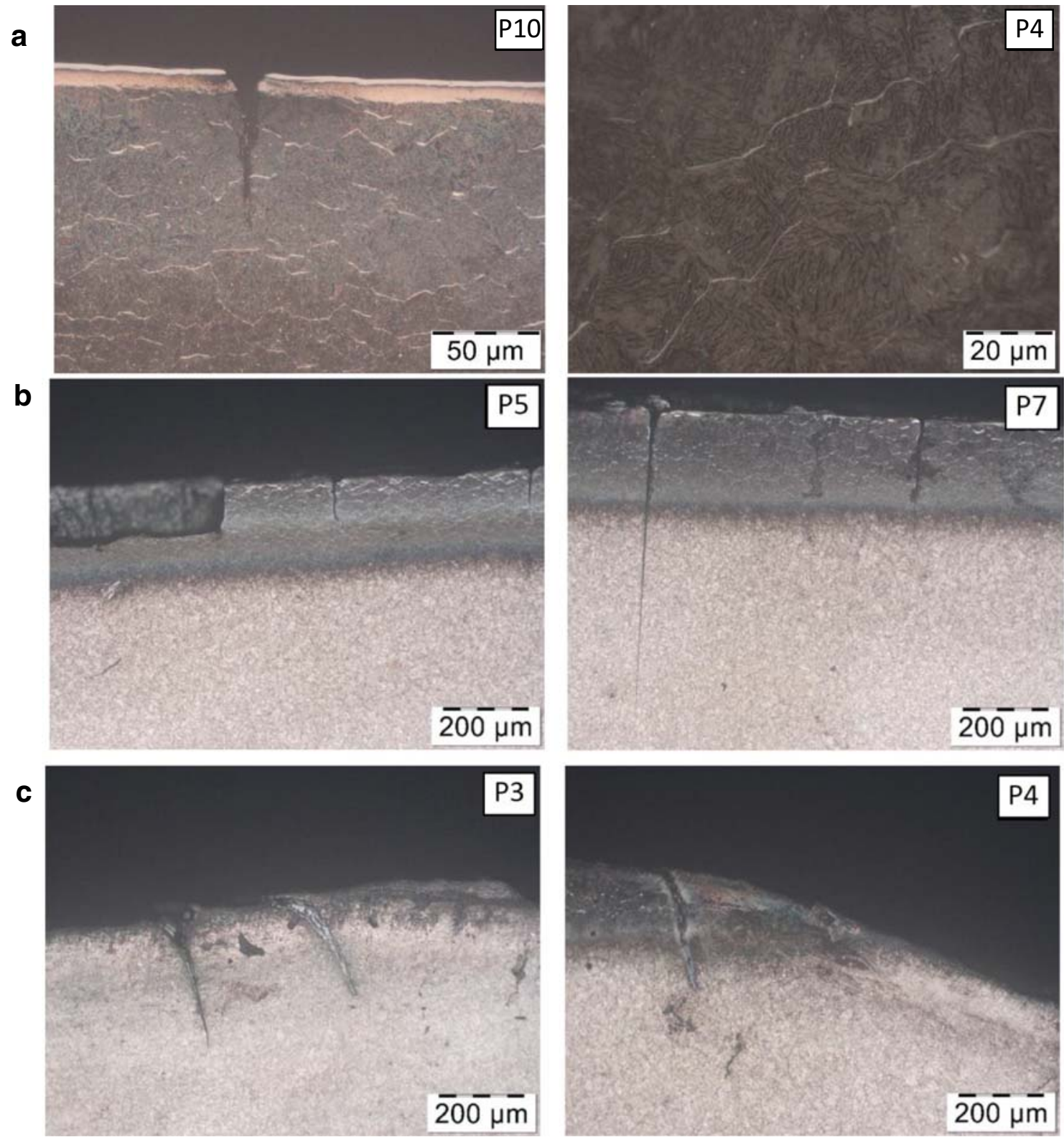

Fig. 10 Microstructure of UNIMAX steel, inserts no. 3 in point a 10 and no. 2 in point 4, b 5 and 7 , and $\mathbf{c} 3$ and 4

structure in any of the examined points. Despite the numerous cracks and spalling of the nitrided layer, the continuity within the whole insert was maintained (Fig. 9c).

Figure 10a shows the nitrided layer together with the PVD coating. The white PVD coating is located on the surface and reaches the thickness in the scope of 1-2 $\mu \mathrm{m}$. Under the PVD coating, there is a nitrided layer $\varepsilon$ and $\gamma^{\prime}$ (by definition, these two phases are present on the surface of the nitrided layer), whose thickness is within the scope of $2-4 \mu \mathrm{m}$. In Fig. 10a, one can clearly see that the nitrided layer for the inserts denoted as no. 3 is richer in nitrides than that nitrided by SECO, with no. 2 , which is proved by a higher number of white nitrides on the grain boundaries. In the microstructure images, no tempering of the structure was observed in points 5,7 , and
13 (Fig. 10b), which are situated on the vertical walls of the insert.

Locally, cracks on the insert surface were noticed, especially in the areas where the surface was not flat. In some areas, the depth of the cracks exceeded $500 \mu \mathrm{m}$, where material losses and spallings were observed in the nitrided layer; however, on the whole length of the flat walls, the layer maintained its continuity. A big number of cycles and the prolonged operation of temperature caused not only degradation of the nitrided layer of insert no. 3 but also tempering of the native material located directly beneath this layer as well as the formation of characteristic bent crack gaps (Fig. 10c), pointing toward the occurrence of plastic deformations. In the areas visible in Fig. 11, the 

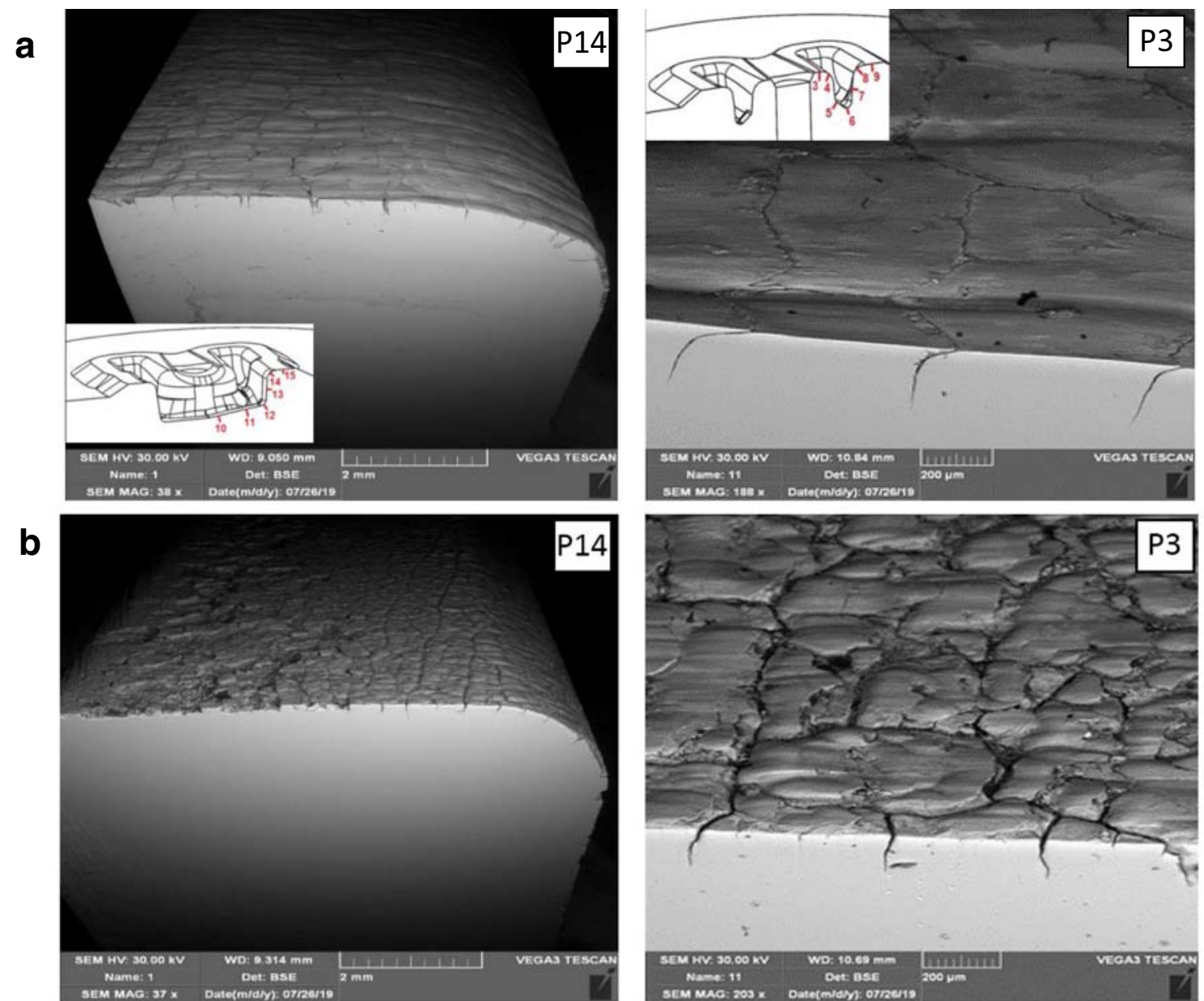

C
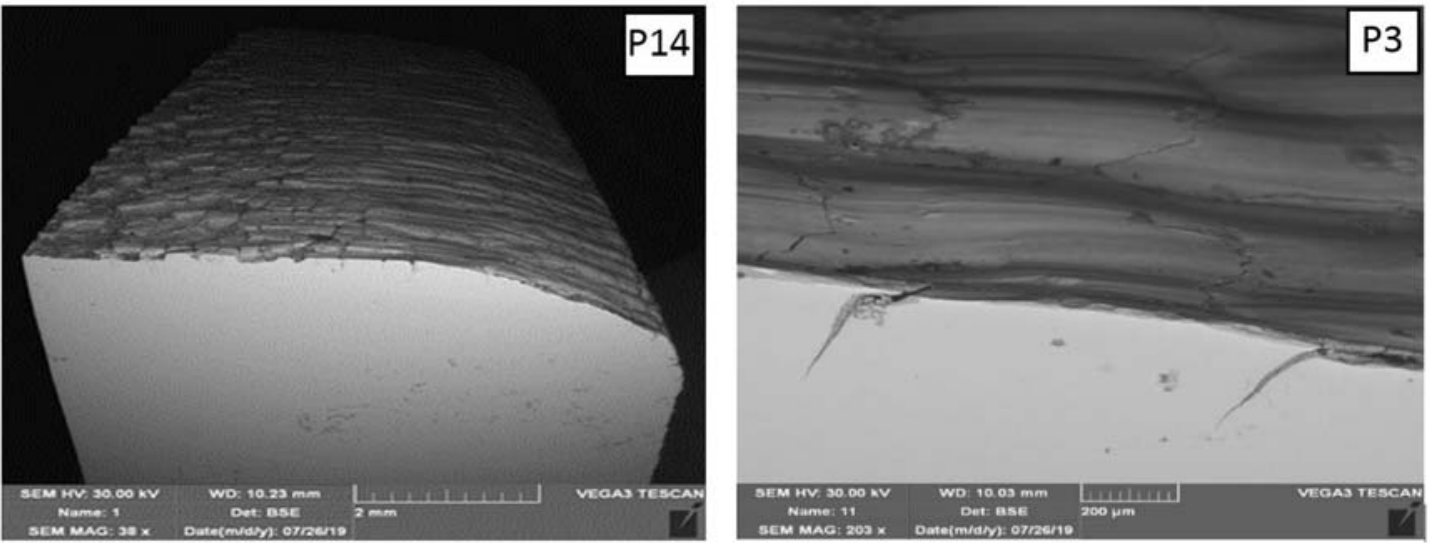

Fig. 11 SEM test results - view of the surface in point 14 and in point 3 in inserts a no.1, b no. 2, and $\mathbf{c}$ no. 3

microstructure is close to that observed in point 14 of insert no.1.

\subsection{SEM analysis of the surface}

The examinations of the inserts' surface were performed by means of a scanning electron microscope VEGA TESCAN-3, operating with the accelerating voltage of $30 \mathrm{kV}$. The analysis of the surface of the selected inserts showed significant differences in the changes on the surfaces of their impressions. Figure 11a presents those tool surfaces on which the material of the forging was clearly flowing (points 14,15 ), forming an outer and inner flash (point 13) between the arms of the forging. Based on the test results for the insert made of the Unimax steel without an additional thermo-chemical treatment, one can observe numerous grooves as well as, probably, remains of the primary network of cracks originating from thermo-mechanical fatigue, due to a large geometrical loss of the material in these 

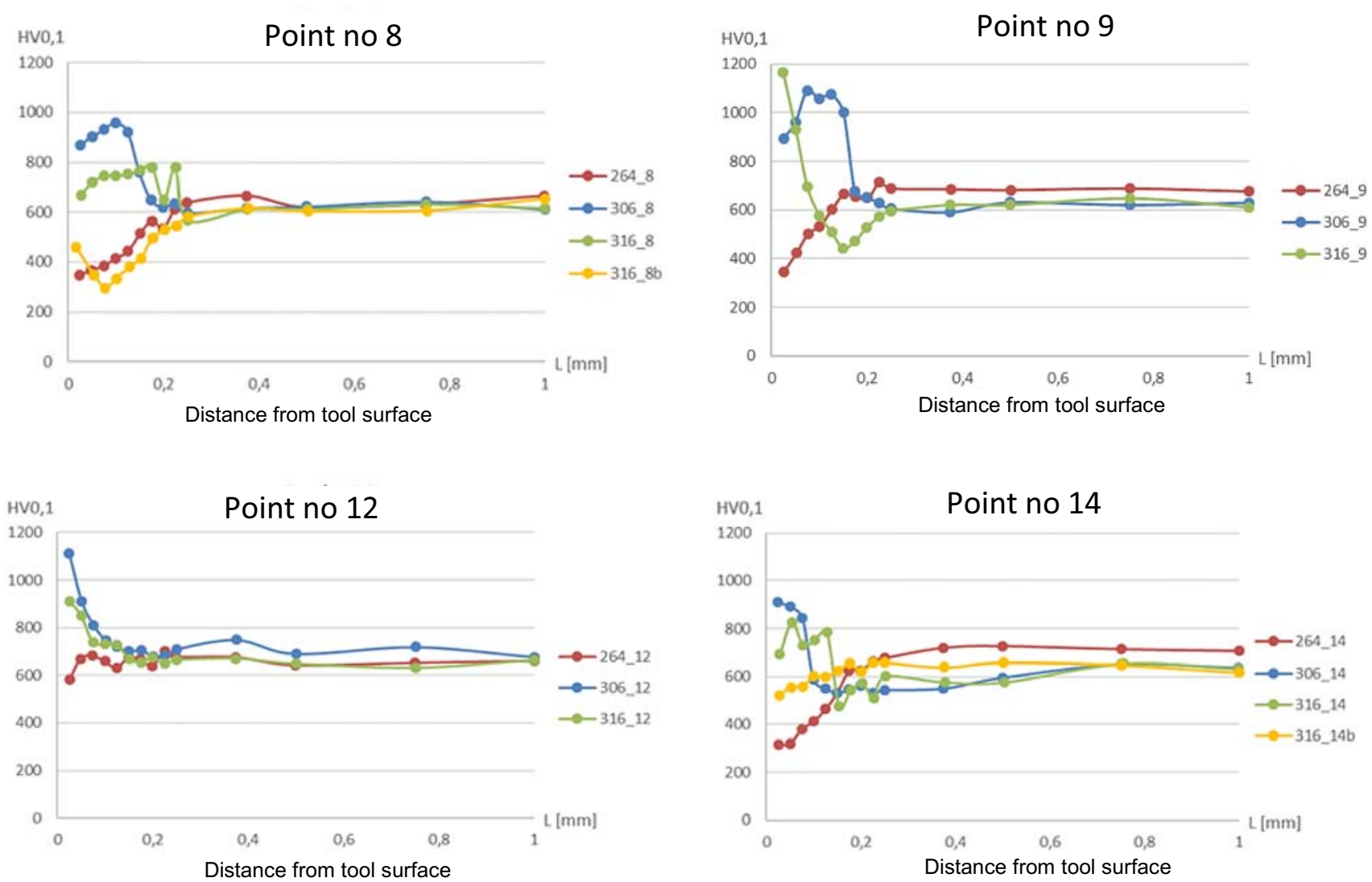

Fig. 12 Measurement results for the selected measurement points for all variants (three die inserts in selected areas)

areas, for the tool that produced 16,000 forgings. One can also observe characteristic bents of the cracks, which points to a significant operation of high temperatures, causing local material tempering as well as cracks bent in the direction of the forging material flow. In turn, for insert no. 2 (Fig. 11b), no characteristic grooves formed as a result of the forging material flow were observed, which makes it possible to establish that the insert material itself did not flow either. These images confirm the microstructure observations, from which it could be inferred that the nitrided layer maintained its continuity on the whole surface of the insert, and so, no plastic deformation of its surface or the formation of grooves took place. However, there is a clear crack network of the layer itself to be observed on the surface of the insert as well as its numerous spallings and losses, which, with further operation of the tool, could cause an intensive material loss as well as rapid wear.

In turn, on the surface of insert no. 3, which originally had a nitrided layer as well as a PVD coating, as it performed a bigger number of cycles, total abrasion and spalling of not only the PVD coating but also the nitrided layer took place, which is confirmed by the microstructure images (Fig. 11c). And so, on the surface of this insert, plastic deformation of the native material as well as the formation of grooves occurred, similarly to the case of insert no. 1. Based on the images with a higher magnification, one can also state that the gaps of the cracks running from the surface of the inserts are perpendicular to the insert only in the case of no. 2. In other two cases, the crack gaps are bent, which are a result of the flow of the insert material.

\subsection{Hardness measurement results}

The hardness tests were carried out by means of a microhardness tester LECO LM-100AT, with the use of the Amh43 computer software, by the Vickers method, with the load of 100 g. Figure 12 shows the results of microhardness measurement for the selected points. The hardness measurements for insert no. 1 in the selected exemplary points 8,9 , and14, i.e., in the areas which are the most exposed to the operation of the temperature and the flow of the material, showed a significant drop of hardness, from the level of over 600HV0.1 to as little as about $300 \mathrm{HV} 0.1$. The hardness measurement for insert no. 2 demonstrated the presence of a nitrided layer, with the hardness of about 1000-1100HV0.1, with the thickness of about $200 \mu \mathrm{m}$. In the selected exemplary areas which were the most exposed to the operation of the temperature and the flow of the forging material (points 8 and 14), the surface of the insert was tempered, as a result of which the hardness dropped even to the level of about $800 \mathrm{HV} 0.1$. Based on the previously performed microstructure and surface analyses, a smaller 
thickness of the nitrided layer in these points was also observed, which is a result of the partial abrasion of the layer (point 14). The hardness measurements of insert no. 3 showed the presence of a nitrided layer, with the hardness exceeding $1100 \mathrm{HV} 0.1$, with the thickness of over $200 \mu \mathrm{m}$.

The higher hardness as well as thickness of the layer is caused by the presence of an additional PVD coating on its surface. What is interesting, in the selected areas, i.e., in points 8,9 , and 14 , a bigger hardness drop of insert no. 3 was observed as compared with insert no. 2 , especially at the distance of about $0.15 \mathrm{~mm}$ from the surface, which is probably caused by a higher number of performed cycles. Additionally, in the selected areas, i.e., in points 8 and 14 for insert no. 3, the distribution of hardness on the surface was determined in the following two areas: where the nitrided layer was still present, and where the layer had completely worn off (the area of the biggest wear of the insert), which were located close to each other. It is clear that, in the areas of the insert's most intensive wear, a total abrasion and destruction of the layer as well as the coating occurred, and the hardness of the material reached a similar level to that for insert no. 1, which had no layer at all.

\section{Summary and conclusions}

The utilitarian aim of the study was to determine the effect of the applied tool material — Unimax — (also, after different treatment variants with the use of surface engineering techniques), in respect of the 1.2344 steel tool for hot operations used so far, on the increase of the hardness of forging tools. The analysis of the industrial forging process supported by temperature measurements as well as numerical modeling enabling the determination of many difficult, or even impossible to establish by other methods, parameters made it possible to point to the key process parameters, which decides about the wear. The first macroscopic observations showed that the best resistance was exhibited by the inserts for variants 2 and 3, although it should be noted that only the introduction of the new tool material itself caused an over twofold increase of hardness. The geometrical analysis of the wear provided valuable information on the degree of wear, and also enabled its quantitative evaluation and a comparison of both tools. It can be inferred from the analysis that the tools made of the Unimax steel without an additional thermo-chemical treatment wear off much faster and in a very irregular manner, as opposed to the tools made of the same steel but after nitriding or a hybrid layer application, for which the tool exploitation proceeds in a stable way. Also, the wear of the insert made of the Unimax steel was more uniform, as opposed to the inserts made of the standard steel 1.2343 examined so far, for which traces of local spalling and damage have been observed, which are also confirmed by the observations performed by means of a scanning microscope. The wear observed during macroscopic analysis was then subjected to careful observation in scanning and optical microscopy. The result of this analysis is to observe the effects of wear on the surface and in the surface layer. This wear was caused by mechanisms that result from the adopted surface treatment. The tool made of Unimax steel was mainly subjected to abrasive wear, which was manifested through abrasive furrows forming along the direction of flow of the material on the surface of the tool. These furrows are deep (up to $1 \mathrm{~mm}$, which was measured in Fig. 6a) and smoothed at the edges (Fig. 11). They are located on the rounded edges near the matrix bridge (Fig. 8). Their presence is undesirable and causes the tool to be withdrawn from use. The nitrided tool underwent other wear mechanisms, among which cracking due to thermal and mechanical fatigue predominated. Observations of the microstructure show small defects in the form of chipping and cracks that are shallow and densely arranged. Wear occurred locally by cracking and chipping fragments from the surface, followed by further abrasive wear in a place weakened by cracks and chipping (Fig. 9). Similar wear but to a lesser extent was observed with the tool with Alvin coating. The presence of the coating led to long-term wear resistance. However, in the areas with the highest load indicated in the FEM analysis (Fig. 4), damage was caused by cracking and chipping, which led to the removal of both the coating and the nitrided layer (Fig. 10).

The obtained results suggest that despite the higher price of the Unimax steel (about 6 euro per $1 \mathrm{~kg}$ ), in the case of the analyzed die inserts ( $1 \mathrm{~kg} / 3$ euro), its application is economically justified. We need to manufacture 2.5 die inserts in relation to 1 die insert made of Unimax steel to achieve similar durability of forging tools. Also, taking into account the costs of the mechanical treatment of the tools and their thermal treatment as well as the costs of the shutdown of the production line resulting from the necessity of replacing the worn tools, the benefits coming from the use of a better tool material are much greater.

It should be pointed out that the results presented in the study were obtained for three variants with three repetitions, which creates the necessity of performing further tests in order to standardize the durability improvement process by way of applying an alternative material together with an additional thermo-chemical treatment as well as to determine the stability and cost-effectiveness of the introduced changes depending on the production scale.

Funding information This study was funded by Narodowe Centrum Badań i Rozwoju grant number TECHMATSTRATEG1/348491/10/ NCBR/2017.

Open Access This article is licensed under a Creative Commons Attribution 4.0 International License, which permits use, sharing, adaptation, distribution and reproduction in any medium or format, as long as you give appropriate credit to the original author(s) and the source, provide a link to the Creative Commons licence, and indicate if changes were made. The images or other third party material in this article are included in the article's Creative Commons licence, unless indicated otherwise in a 
credit line to the material. If material is not included in the article's Creative Commons licence and your intended use is not permitted by statutory regulation or exceeds the permitted use, you will need to obtain permission directly from the copyright holder. To view a copy of this licence, visit http://creativecommons.org/licenses/by/4.0/.

\section{References}

1. Brucelle O, Gerard B (1999) Methodology for service life increase of hot forging tools. J Mater Process Technol 87(1-3):237-246

2. Lange K, Cser L, Geiger M, Kals JAG (1993) Tool life and tool quality in bulk metal forming. Proc Inst Mech Eng B J Eng Manuf 207:223-239

3. Marek H (2016) Review of selected methods of increasing the life of forging tools in hot die forging processes. Arch Civ Mech Eng 16(4):845-866

4. Lange K (1997) Modern metal forming technology for industrial production. J Mater Process Technol 2-13:2-13

5. Marek H, Ziemba J (2019) Lubrication in hot die forging processes. Proc Inst Mech Eng, Part J 233(5):663-675

6. Taylan A, Gracious N, Gangshu S (2005) Cold and hot forging fundamentals and application. ASM International. ASM metals handbook 14:337-338

7. Gronostajski Z, Marcinak K et al (2014) A review of the degradation mechanisms of the hot forging tools. Arch Civ Mech Eng 14(4):528-539

8. Hawryluk M (2016) Methods of analysis and increasing the durability of forging tools used in hot die forging processes, Radom: Scientific Publisher of the Institute for Sustainable Technologies

9. Weroński A (2019) Thermal fatigue of metals. CRC Press, Boca Raton

10. Lapovok R, Smirnov S, Shveykin V (2000) Damage mechanics for the fracture prediction of metal forming tools. Int J Fract 103(2): $111-126$

11. Choi C, Groseclose A, Altan T (2012) Estimation of plastic deformation and abrasive wear in warm forging dies. J Mater Process Technol 212(8):1742-1752

12. Kima DH, Leeb HC, Kimc BM, Kimd KH (2012) Estimation of die service life against plastic deformation and wear during hot forging processes. J Mater Process Technol 212:1742-1752

13. Anders P, Hogmark S, Bergström J (2004) Simulation and evaluation of thermal fatigue cracking of hot work tool steels. Int J Fatigue 10:1095-1107

14. Katunin A (2011) The conception of the fatigue model for layered composites considering thermal effects. Arch Civil Mech Eng 11(2):333-342

15. Persson A, Hogmark S, Bergstroma J (2005) Thermal fatigue cracking of surface engineered hot work tool steels. Surf Coat Technol 191:216-227

16. Berti GA, Monti M (2005) Thermo-mechanical fatigue life assessment of hot forging die steel. Fatigue Fract Eng Mater Struct 28(11): 1025-1034

17. Pengfei G, Xinggang $Y$ et al (2019) Formation mechanisms and rules of typical types of folding defects during die forging. Int $\mathrm{J}$ Adv Manuf Technol 104(1-4):1603-1612

18. Gao PF, Fei MY, Yan XG, Wang SB, Li YK, Xing L, Wei K, Zhan M, Zhou ZT, Keyim Z (2019) Prediction of the folding defect in die forging: a versatile approach for three typical types of folding defects. J Manuf Process 39:181-191

19. Gronostajski Z, Hawryluk M, Jakubik J et al (2015) Solution examples of selected issues related to die forging. Arch Metall Mater 60(4):2773-2781
20. Gronostajski Z, Kaszuba M, Polak S et al (2011) Die profile optimization for forging constant velocity joint casings. Arch Metall Mater 56(2):551-558

21. Lu B, Ou H, Long H (2011) Die shape optimisation for net-shape accuracy in metal forming using direct search and localised response surface methods. Struct Multidiscip Optim 44:529-545

22. Marek H, Kaszuba M et al (2016) Systems of supervision and analysis of industrial forging processes. Eksploatacja i Niezawodność - Maintenance and Reliability 18(3):315-324

23. Gronostajski Z, Hawryluk M, Kaszuba M, Widomski P, Ziemba J (2017) Application of the reverse 3D scanning method to evaluate the wear of forging tools divided on two selected areas. Int $\mathrm{J}$ Automot Technol 18(4):653-662

24. Joshy S, Jayadevan KR, Ramesh A et al (2019) Microstructural evolution and microhardness response of $\mathrm{H} 11$ hot forging dies. World J Eng 16(5):573-581

25. Paschke H, Yilkiran T, Lippold L et al (2015) Adapted surface properties of hot forging tools using plasma technology for an effective wear reduction. Wear 330:429-438

26. Vander Voort GF (2004) ASM Handbook Volume 9: Metallography and Microstructures. vol. 9, Materials Park, Ohio,

27. Montanari R, Varone A (2019) Processing-Structure-Property Relationships in Metals, MDPI@Books

28. Gronostajski Z, Widomski P, Kaszuba M (2018) Analiza trwałości wkładek matrycowych do kucia na gorąco widłaka wykonanych ze stali $1.2343 \mathrm{i}$ UNIMAX/analysis of the durability of the forging die inserts for fork-typ forgings made of 1.2343 and UNIMAX steel. Rudy Met Niezelaz 63(8):9-18

29. Gulsah Aktas C, Seyda P, Hakan AS (2017) Tribological behavior of $\mathrm{CrN}$-coated Cr-Mo-V steels used as die materials. Int J Miner Metall Mater 24(12):1394-1402

30. Gracia-Escosa E, Garcia I, de Damborenea JJ et al (2010) Friction and wear behaviour of tool steels sliding against 22MnB5 steel. J Mater Res Technol 6(3):241-250

31. Hawryluk M, Gronostajski Z, Kaszuba M, Polak S, Widomski P, Ziemba J, Smolik J (2017) Application of selected surface engineering methods to improve the durability of tools used in precision forging. Int J Adv Manuf Technol 93(5-8):2183-2200

32. Gronostajski Z, Widomski P, Kaszuba M, Zwierzchowski M, Polak S, Piechowicz Ł, Kowalska J, Długozima M (2020) Influence of the phase structure of nitrides and properties of nitrided layers on the durability of tools applied in hot forging processes. J Manuf Process $52: 247-262$

33. Legutko S, Meller A, Gajek M (2013) Investigation of hybrid layers on the life time of hot forging dies. Metalurgija 52(2):185-188

34. Smolik J, Mazurkiewicz A (2011) Comparative analysis of wear mechanism of different types of forging dies. Arch Mater Sci Eng 49:40-45

35. Hawryluk M, Gronostajski Z, Kaszuba M, Polak S, Widomski P, Smolik J, Ziemba J (2017) Analysis of the wear of forging tools surface layer after hybrid surface treatment. Int J Mach Tools Manuf 114:60-71

36. Min Y, Xu L, Wu X (2002) Influence of surface heat treatment on thermal fatigue behaviors of hot work steel. 6th Int Tool Conf 63 76

37. Wang X, Zhou T et al (2019) Effects of laser on the non-smooth surface in improving the durability of hot forging tools. Opt Laser Technol 119:105598

38. Gronostajski Z, Pater Z, Madej L et al (2019) Recent development trends in metal forming. Arch Civil Mech Eng 3:898-941

39. Hawryluk M, Ziemba J, Dworzak Ł, Kaczyński P, Kasprzak M (2018) Wear analysis of forging tools used in the hot forging processes using 3D reverse scanning techniques and coolinglubricating system. Int J Adv Manuf Technol 97(5-8):2009-2018

40. Hawryluk M, Gronostajski Z, Ziemba J, Dworzak Ł, Jabłoński P, Rychlik M (2018) Analysis of the influence of lubrication 
conditions on tool wear used in hot die forging processes. Eksploatacja i Niezawodność - Maintenance and Reliability 20(2): 169-176

41. Lee SW, Jo JW et al (2019) Effect of friction conditions on material flow in FE analysis of $\mathrm{Al}$ piston forging process. Int $\mathrm{J}$ Precis Eng Manuf 20(10):1643-1652
Publisher's note Springer Nature remains neutral with regard to jurisdictional claims in published maps and institutional affiliations. 